\title{
Posterolateral Part of the Prostate
}

National Cancer Institute

\section{Source}

National Cancer Institute. Posterolateral Part of the Prostate. NCI Thesaurus. Code C48663.

The part of the prostate gland that is lateral and posterior. 